\title{
The intraocular penetration of cefuroxime after parenteral administration
}

\author{
A. B. RICHARDS, ${ }^{1}$ A. J. BRON, ${ }^{2}$ B. MCLENDON, ${ }^{2}$ M. R. K. KENNEDY, ${ }^{3}$ AND \\ S. R. WALKER ${ }^{3}$
}

From the ${ }^{1}$ Royal Berkshire Hospital, ${ }^{2}$ Oxford Eye Hospital, and ${ }^{3}$ Glaxo-Allenburys Research Ltd.

SUMMARY Cefuroxime (Zinacef) is a new second generation cephalosporin which is resistant to $\beta$-lactamases produced by both Gram-negative and Gram-positive organisms, with an antibacterial spectrum that includes practically all likely ocular pathogens except pseudomonas. It is shown to penetrate into the eye after intravenous $(1.5 \mathrm{~g})$ or intramuscular $(1 \mathrm{~g})$ injection and achieve therapeutic concentrations, with absence of side effects. Cefuroxime is therefore a useful antibiotic for ophthalmic infections and should have a role in combination with gentamicin in intraocular infections, particularly those of unknown aetiology.

The devastating effect of severe bacterial infections of the eye and the development of resistant organisms to the antibiotics used demand that a constant appraisal be made of the ocular pharmacodynamics and pharmacokinetics of new antibacterial agents. There is often difficulty in isolating causative organisms in ophthalmology, and thus the search continues for broader spectrum and safer antibiotics.

Cephaloridine and cephalothin are effective broad spectrum injectable antibiotics. The penetration of cephaloridine (Riley et al., 1968; Records, 1968, 1969a, 1969b; Richards et al., 1972) and of cephalothin (Mizukawa et al., 1965; Hatano et al., 1966) into human aqueous has been studied after parenteral administration. It has been shown that adequate therapeutic levels of both these cephalosporins are achieved in the primary aqueous after injection, but cephaloridine shows superior ocular penetration and in addition gives less pain at the site of intramuscular injection.

The major defect of these first-generation cephalosporins is that they are hydrolysed by the $\beta$-lactamases of many Gram-negative bacteria. However, the newer cephalosporins such as cefamandole, cefoxitin, and cefuroxime (O'Callaghan, 1975) have a much broader spectrum of activity (Table 1), the 2 latter mainly because of a substantially increased resistance to many bacterial $\beta$ lactamases produced by a number of Gram-negative organisms.

Address for reprints: Dr S. R. Walker, Medical Division, Glaxo-Allenburys Research Ltd., Greenford, Middlesex UB6 0HE
Table 1 In-vitro activity of cefuroxime

\begin{tabular}{lc}
\hline Organism & Sensitivity \\
\hline Gram-positive & \\
Staphylococcus aureus & ++ \\
Streptococcus pneumoniae & +++ \\
Streptococcus pyogenes & +++ \\
Gram-negative & \\
Haemophilus influenzae & +++ \\
Escherichia coli & ++ \\
Klebsiella pneumoniae & ++ \\
Proteus mirabilis & ++ \\
Pseudomonas aeruginosa & $\mathbf{R}$ \\
\hline
\end{tabular}

+++ indicates $\mathbf{M I C}<1 \mu \mathrm{g} / \mathrm{ml}$.

++ indicates MIC $1-8 \mu \mathrm{g} / \mathrm{ml}$.

$R \quad$ indicates MIC $>125 \mu \mathrm{g} / \mathrm{ml}$.

Axelrod and Kochman (1976) have studied the intraocular penetration of cefamandole in 7 patients who were undergoing elective cataract extraction. They showed that after an intravenous or intramuscular injection of $1 \mathrm{~g}$, aqueous levels of up to $1 \cdot 1 \mu \mathrm{g} / \mathrm{ml}$ were seen between 1.1 and 2.5 hours after injection, though in 2 of the patients no cefamandole was detected in the aqueous 4 hours after parenteral administration.

The purpose of this study was to determine the aqueous levels of cefuroxime after an intramuscular or intravenous dose in patients undergoing routine cataract extraction. 


\section{Patients and methods}

Sixty patients ( 27 male, 33 female; age range, 36 to 93 years) who were about to undergo cataract extraction were selected for study. After being informed of the nature of the study patients gave their informed consent to an additional procedure being carried out. Half the patients had their operation at the Oxford Eye Hospital and the others at the Royal Berkshire Hospital. A similar protocol was followed in each centre, the only difference being that in Oxford patients received cefuroxime (1 or $1.5 \mathrm{~g}$ ) intravenously, whereas in Reading cefuroxime $(1 \mathrm{~g})$ was given intramuscularly.

All patients with a history of allergy were excluded from the study, and no patient received topical prophylactic antibiotics. Cefuroxime was administered between 0.5 and 6 hours before the time of aqueous tap.

After the patient had been anaesthetised and the eye prepared, before the opening of the anterior chamber, the globe was grasped over the medial rectus and the chamber entered with a fine aspiration needle (No. 27) on a Mantoux syringe through the presection groove. With the bevel down a sample of aqueous was removed $(100$ to $200 \mu \mathrm{l})$. The chamber was reformed with Ringer's saline, though the paracentesis wound and cataract surgery proceeded in routine fashion.

The aqueous sample was placed in a microcentrifuge tube, capped and labelled with a study number, and stored at $-40^{\circ} \mathrm{C}$. A simultaneous venous blood sample was taken, the plasma being removed for storage at $-40^{\circ} \mathrm{C}$ until analysis.

Cefuroxime was assayed in the plasma and aqueous by the agar diffusion method using Bacillus subtilis $1904 \mathrm{E}$ as the assay organism.

\section{Results}

The details of the patients studied and plasma and aqueous levels of cefuroxime obtained are given in Table 2 . Thirty patients received $1 \mathrm{~g}$ of cefuroxime by intramuscular injection, and the resulting aqueous levels measured between 0.5 and 6 hours after injection ranged from $<0.3$ to $2 \cdot 2 \mu \mathrm{g} / \mathrm{ml}$ (Fig. 1), with a median value of $0.9 \mu \mathrm{g} / \mathrm{ml}$. Eleven patients received $1 \mathrm{~g}$ of cefuroxime and 19 patients $1.5 \mathrm{~g}$ of cefuroxime intravenously. The median aqueous level measured between 25 minutes and 5 hours after administration by this route was $1.6 \mu \mathrm{g} / \mathrm{ml}$ (range, 0.5 to $3.1 \mu \mathrm{g} / \mathrm{ml}$ ) for the $1.5 \mathrm{~g}$ dose and $1.7 \mu \mathrm{g} / \mathrm{ml}$ (range, $<0.3$ to $5.7 \mu \mathrm{g} / \mathrm{ml}$ ) for the $1 \mathrm{~g}$ dose (Fig. 1). Thus, the cefuroxime levels in the aqueous humour were higher after intravenous than after intramuscular administration (Figs. 1 and 2), with the levels
Table 2 Aqueous humour levels of cefuroxime after parenteral administration

\begin{tabular}{|c|c|c|c|c|c|c|}
\hline Patient & $\begin{array}{l}\text { Age } \\
(y r)\end{array}$ & Sex & $\begin{array}{l}\text { Time } \\
\text { (h) }\end{array}$ & $(\min )$ & $\begin{array}{l}\text { Plasma } \\
\text { level } \\
(\mu \mathrm{g} / \mathrm{ml})\end{array}$ & $\begin{array}{l}\text { Aqueous } \\
\text { level } \\
(\mu g / m l)\end{array}$ \\
\hline \multicolumn{7}{|l|}{$1 \mathrm{gIM}$} \\
\hline 1 & 65 & $\mathrm{~F}$ & - & 30 & $17 \cdot 8$ & - \\
\hline 2 & 77 & $F$ & - & 45 & $35 \cdot 3$ & - \\
\hline 3 & 65 & $F$ & 1 & - & $27 \cdot 0$ & 0.8 \\
\hline 4 & 78 & $F$ & 1 & - & $5 \cdot 8$ & 0.5 \\
\hline 5 & 72 & $\mathrm{~F}$ & 1 & - & $25 \cdot 6$ & 0.5 \\
\hline 6 & 68 & $\mathrm{~F}$ & 1 & 30 & $29 \cdot 7$ & $<0.3$ \\
\hline 7 & 43 & $\mathbf{M}$ & 1 & 30 & $14 \cdot 1$ & $<0.3$ \\
\hline 8 & 65 & $F$ & 1 & 45 & $43 \cdot 1$ & 0.9 \\
\hline 9 & 72 & $\mathbf{M}$ & 2 & - & $12 \cdot 3$ & $<0.3$ \\
\hline 10 & 86 & $\mathbf{M}$ & 2 & - & $27 \cdot 1$ & $1 \cdot 3$ \\
\hline 11 & 73 & $\mathbf{M}$ & 2 & - & 15.9 & 1.0 \\
\hline \multirow[t]{2}{*}{12} & 76 & $F$ & 2 & 25 & - & 0.8 \\
\hline & & & 2 & 30 & $36 \cdot 7$ & - \\
\hline 13 & 78 & $\mathbf{M}$ & 2 & 30 & $15 \cdot 2$ & $0 \cdot 8$ \\
\hline 14 & - & $F$ & 2 & 35 & $32 \cdot 3$ & 0.9 \\
\hline 15 & 73 & $\mathbf{M}$ & 2 & 40 & $24 \cdot 6$ & 1.0 \\
\hline 16 & 86 & $\mathrm{~F}$ & 2 & 45 & - & 1.8 \\
\hline 17 & 77 & $\mathbf{M}$ & 3 & - & $21 \cdot 1$ & - \\
\hline 18 & 64 & $F$ & 3 & - & $12 \cdot 6$ & 0.7 \\
\hline 19 & 73 & $\mathbf{M}$ & 3 & 15 & $7 \cdot 8$ & $1 \cdot 1$ \\
\hline 20 & 73 & $\mathbf{M}$ & 3 & 15 & $<0.1$ & $<0.3$ \\
\hline 21 & 75 & $\mathbf{M}$ & 3 & 15 & $25 \cdot 3$ & $1 \cdot 7$ \\
\hline 22 & 69 & $\mathrm{~F}$ & 4 & - & $12 \cdot 7$ & $<0.3$ \\
\hline 23 & 80 & $\mathbf{M}$ & 4 & - & $17 \cdot 9$ & $1 \cdot 1$ \\
\hline 24 & 70 & $F$ & 4 & 05 & 23.0 & 1.9 \\
\hline \multirow[t]{2}{*}{25} & 82 & $\mathbf{M}$ & 4 & 07 & - & $2 \cdot 2$ \\
\hline & & & 4 & 17 & 30.9 & - \\
\hline 26 & 74 & $\mathbf{F}$ & 4 & 30 & $19 \cdot 8$ & 1.4 \\
\hline 27 & 73 & $\mathbf{F}$ & 4 & 30 & 12.0 & 1.8 \\
\hline 28 & 77 & $\mathbf{F}$ & 5 & - & $7 \cdot 9$ & - \\
\hline 29 & 64 & - & 5 & 30 & 8.9 & $1 \cdot 1$ \\
\hline 30 & 78 & $\mathbf{M}$ & 6 & - & $8 \cdot 5$ & 0.9 \\
\hline \multicolumn{7}{|l|}{$1 \mathrm{gIV}$} \\
\hline 31 & 78 & $\mathbf{M}$ & - & 25 & - & $<0.3$ \\
\hline 32 & 85 & $F$ & 1 & 10 & $39 \cdot 1$ & $1 \cdot 3$ \\
\hline 33 & 88 & $\mathbf{M}$ & 1 & 25 & $66 \cdot 5$ & 5.7 \\
\hline 34 & 79 & $\mathbf{M}$ & 1 & 25 & $49 \cdot 5$ & $1 \cdot 1$ \\
\hline 35 & 80 & $\mathbf{F}$ & $i$ & 25 & $33 \cdot 1$ & - \\
\hline 36 & 83 & $\mathbf{M}$ & 1 & 40 & 50.7 & $2 \cdot 1$ \\
\hline 37 & 93 & $F$ & 1 & 55 & 57.0 & $0 \cdot 7$ \\
\hline 38 & 87 & $F$ & 3 & 05 & $19 \cdot 1$ & 1.8 \\
\hline 39 & 90 & $\mathbf{M}$ & 3 & 10 & $23 \cdot 3$ & 10 \\
\hline \multirow[t]{2}{*}{40} & 36 & $\mathbf{M}$ & 4 & - & - & $<0.3$ \\
\hline & & & 4 & 45 & $4 \cdot 7$ & - \\
\hline 41 & 68 & $\mathbf{F}$ & 5 & - & 11.9 & $1 \cdot 7$ \\
\hline \multicolumn{7}{|c|}{$1.5 \mathrm{~g} \mathrm{IV}$} \\
\hline 42 & 58 & $\mathbf{M}$ & - & 40 & $183 \cdot 2$ & $2 \cdot 0$ \\
\hline \multirow{2}{*}{43} & 73 & $\mathbf{M}$ & - & 45 & - & $1 \cdot 3$ \\
\hline & & & - & 50 & $127 \cdot 4$ & - \\
\hline \multirow[t]{2}{*}{44} & 83 & $\mathrm{~F}$ & - & 48 & $36 \cdot 2$ & - \\
\hline & & & 1 & 28 & - & 2.9 \\
\hline 45 & 72 & $F$ & - & 55 & $\overline{50} \cdot 8$ & 1.4 \\
\hline 46 & 86 & $\mathbf{M}$ & $\overline{1}$ & - & 181.8 & 1.6 \\
\hline 47 & 79 & $\mathbf{M}$ & 1 & $\overline{08}$ & $\begin{array}{r}47.4 \\
\end{array}$ & $2 \cdot 2$ \\
\hline 48 & 86 & $\mathbf{M}$ & 1 & 09 & $32 \cdot 2$ & - \\
\hline 49 & 76 & $\mathrm{~F}$ & 1 & 10 & $60 \cdot 6$ & 2.4 \\
\hline 50 & 64 & $\mathbf{M}$ & 1 & 15 & 53.7 & 1.5 \\
\hline 51 & 83 & $F$ & 1 & 15 & 17.9 & 1 \\
\hline 52 & 77 & $F$ & 1 & 15 & 116.0 & $\overline{3 \cdot 1}$ \\
\hline 53 & 73 & $\mathbf{F}$ & 2 & - & 56.8 & $1 \cdot 2$ \\
\hline 54 & 76 & $F$ & 2 & 08 & $31 \cdot 2$ & $2 \cdot 2$ \\
\hline 55 & 84 & $\mathbf{F}$ & 2 & 15 & $78 \cdot 7$ & 2.5 \\
\hline 56 & 66 & $\mathrm{~F}$ & 2 & 45 & 78.0 & $2 \cdot 3$ \\
\hline 57 & 62 & $\mathrm{~F}$ & 3 & - & 9.7 & $1 \cdot 0$ \\
\hline 58 & 83 & $\mathrm{~F}$ & 3 & 05 & $18 \cdot 2$ & 1.6 \\
\hline 59 & 61 & $F$ & 4 & 53 & $2 \cdot 7$ & 0.5 \\
\hline 60 & 66 & $\mathbf{M}$ & - & - & $23 \cdot 3$ & 0.7 \\
\hline
\end{tabular}




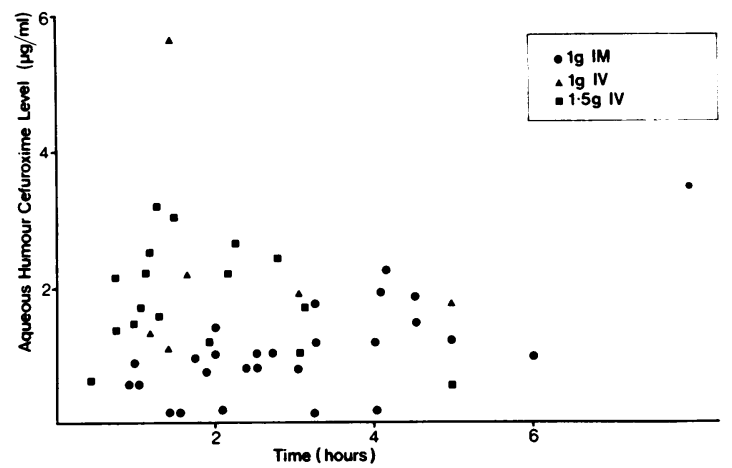

Fig. 1 Aqueous humour levels of cefuroxime after parenteral administration

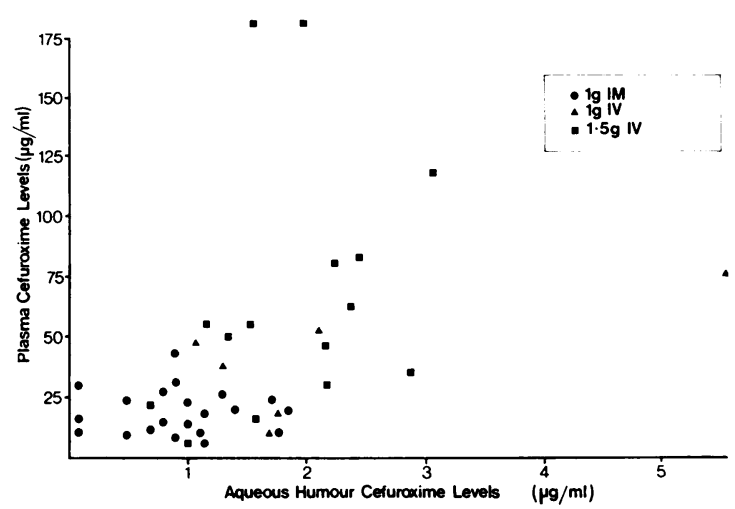

Fig. 2 Plasma and aqueous humour levels of cefuroxime

in some patients reaching more than $10 \%$ of the corresponding plasma level.

\section{Discussion}

This study shows that significant levels of cefuroxime are achieved in the primary aqueous after parenteral administration. The levels obtained are very much greater than the minimum inhibitory concentrations (MICs) of those organisms (O'Callaghan et al., 1976) causing the majority of bacterial infections of the eye. In addition, this study was carried out in uninflamed eyes, and penetration will probably be higher under inflamed conditions (Richards et al., 1972).

However, although cefuroxime should be of value in ophthalmology, its poor antibacterial activity against pseudomonas means that for severe corneal and intraocular infections when no causative organisms can be detected combination treatment with an aminoglycoside would be logical.

We have shown that higher aqueous levels of cefuroxime were achieved 2 or more hours after the intramuscular administration of $1 \mathrm{~g}$ compared with the first 2-hour period. Moreover, even higher levels were obtained when this dose or the $1.5 \mathrm{~g}$ dose were given intravenously. The conclusion can be drawn that to provide adequate antibacterial cover during ocular surgery an intravenous dose of $1.5 \mathrm{~g}$ cefuroxime should be given 1 to 2 hours before the operation begins.

A previous report of the intraocular penetration of cephaloridine commented on the usefulness of this cephalosporin in treating syphilitic patients (minimum immobilisation concentration against Treponema pallidum is $0.055 \mu \mathrm{g} / \mathrm{ml}$ ). There are reports that after treatment with penicillin the survival of Treponema pallidum is favoured in the eye because of the poor penetration of penicillin into this site (Sparling, 1971). Cefuroxime, with its good intraocular penetration and high activity against this spirochaete (minimum immobilisation concentration of $0.0125 \mu \mathrm{g} / \mathrm{ml})$, might therefore have an important role in the treatment of tertiary syphilis.

The authors thank Miss Susan Bristow for typing this paper.

References

Axelrod, J. L., and Kochman, R. S. (1976). Cefamandole levels in the human eye. 16th Interscience Conference on Antimicrobial Agents in Chemotherapy. October 1976. Chicago, USA.

Hatano, H., Kayaba, T., and Shiga N. (1966). Use of cephalothin and cephaloridine in ophthalmology. Japanese Journal of Clinical Ophthalmology, 20, 805-810.

Mizukawa, T., Azuma, I., and Kawaguchi, S. (1965). Intraocular distribution of cephalothin and cephaloridine. Journal of Antibiotics, Ser. B (Tokyo edition), 18, 525-526.

O'Callaghan, C. H. (1975). Classification of cephalosporins by their antibacterial activity and pharmacokinetic properties. Journal of Antimicrobial Chemotherapy, 1 (Suppl. 1), 1-12.

O'Callaghan, C. H., Sykes, R. B., Ryan, D. M., Foord, R. D., and Muggleton, P. W. (1976). Cefuroxime-a new cephalosporin antibiotic. Journal of Antibiotics, 29, 29-37.

Records, R. E. (1968). Intraocular penetration of cephalothin. I. Animal studies. II. Human studies. American Journal of Ophthalmology, 66, 436-440; 441-443.

Records, R. E. (1969a). Intraocular penetration of cephaloridine: observations in experimental animal and human eyes. Archives of Ophthalmology, 81, 331-335.

Records, R. E. (1969b). The cephalosporins in ophthalmology. Survey of Ophthalmology, 13, 345-354.

Richards, A. B., Bron, A. J., Rice, N. G. C., Fells. P., Marhall, M. J., and Jones, B. R. (1972). Intraocular penetration of cephaloridine. British Journal of Ophthalmology, 56, 531-537.

Riley, F. C., Boyle, G. L., and Leopold, I. H. (1968). Intraocular penetration of cephaloridine in humans. American Journal of Ophthalmology, 66, 1042-1049.

Sparling, P. F. (1971). Diagnosis and treatment of syphilis. New England Journal of Medicine, 284, 642-653. 